\title{
Microwave Assisted Paal-Knorr Reaction. A Rapid Approach to Substituted Pyrroles and Furans
}

\author{
Giacomo Minetto Luca F. Raveglia ${ }^{\S}$ and Maurizio Taddei*
}

Dipartimento Farmaco Chimico Tecnologico, Università degli Studi di Siena, Via A. Moro, 53100 Siena, Italy and NiKem Research srl, Via Zambeletti 2520021 Baranzate di Bollate, Milano Italy.

Supplementary material.

Pag 2 General procedures for compounds 4, 14 and 10

3

4 5

6
${ }^{1} \mathrm{H}$ NMR 4

${ }^{1}$ H NMR 14

${ }^{13} \mathrm{C}$ NMR 14

${ }^{1}$ H NMR 18

${ }^{1}$ H NMR 19

${ }^{13} \mathrm{C}$ NMR 19

${ }^{1} \mathrm{H}$ NMR 20

${ }^{1} \mathrm{H}$ NMR 21

${ }^{13} \mathrm{C}$ NMR 21

${ }^{1}$ H NMR 22

${ }^{1}$ H NMR 10 


\section{Methyl 2-(1-oxo-1-phenyl-methyl)-5,5-dimethyl-4-oxo-hexanoate (4). General procedure.}

Diethyl zinc ( $30 \mathrm{~mL}$ of a $1.0 \mathrm{M}$ solution in hexane, $30 \mathrm{mmol}$ ) was dissolved into dry dichloromethane $(60 \mathrm{~mL})$ under nitrogen and the mixture cooled to $0^{\circ} \mathrm{C}$. Diiodo methane $(2,4 \mathrm{~mL}, 30 \mathrm{mmol})$ was slowly added and the mixture stirred for $10 \mathrm{~min}$. After the formation of a white precipitate, methyl 4,4 dimethyl-3-oxopentanoate 1 (1,2 $\mathrm{mL}$, $7.3 \mathrm{mmol}$ ) was added and the reaction was stirred for $30 \mathrm{~min}$. Benzaldehyde (previously distilled under vacuum and collected over molecular sieves) $(0.78 \mathrm{~mL}, 7,68 \mathrm{mmol})$ was added and the mixture stirred at $0^{\circ} \mathrm{C}$ for $1 \mathrm{~h}$. Silica gel $(20.0 \mathrm{~g})$ was added and the mixture stirred at room temperature for additional $30 \mathrm{~min}$. The mixture was filtered under vacuum and the solvent evaporated. The crude $(2.26 \mathrm{~g})$ was dissolved in dry dichloromethane, PCC $(3.3 \mathrm{~g}, 15.3 \mathrm{mmol})$ was added and the mixture stirred at room temperature untill tlc analysis (eluent hexane: AcOEt 5: 1) showed disappearance of the starting material. Eventually, additional PCC could be added. The mixture was passed through a short path of silica gel and eluted with dichloromethane. The solvent was collected and evaporated under vacuum to give product 4 (1,9 g, 90\% yield). ${ }^{1} \mathrm{H}$ NMR spectrum enclosed.

\section{Methyl 1-benzyl-5-tert-butyl-2-phenyl-1H-pyrrole-3-carboxylate. 14.}

Product 4 (1g, 3,44 mmol) was dissolved into acetic acid (3 mL) into a $50 \mathrm{~mL}$ roundbottom flask equipped with a stir bar and a reflux condenser. Benzyl amine (1.84 g, 17.2 mmol) was added and the flask inserted into the cavity of a Discovery Microwave System apparatus (from CEM) and heated at $150 \mathrm{~W}$ for 12 min (internal temperature $\left.170^{\circ} \mathrm{C}\right)$.

The mixture was diluted with AcOEt and the solvent washed several times with a saturated solution of $\mathrm{NaHCO}_{3}$. The organic layer was dried over anhydrous $\mathrm{Na}_{2} \mathrm{SO}_{4}$ and the solvent evaporated. The ${ }^{1} \mathrm{H}$ NMR spectrum of the crude showed the presence of compound 14 together with benzylamine acetate. The required pyrrole was purified by flash chromatography (eluent Hexane: AcOEt 8: $1, \mathrm{R}_{\mathrm{f}}=0.37$ ) that gave product 14 (0.87 g, 70\% yield). ). ${ }^{1} \mathrm{H}$ and ${ }^{13} \mathrm{C}$ NMR spectra are enclosed.

\section{Methyl 5-tert-butyl-2-(2-phenyethyl)furane-3-carboxylate. 12}

Product $5(0.5 \mathrm{~g}, 1,64 \mathrm{mmol})$ was dissolved into $\mathrm{EtOH}(2 \mathrm{~mL})$ into a $50 \mathrm{~mL}$ roundbottom flask equipped with a stir bar and a reflux condenser. $\mathrm{HCl} 0.1 \mathrm{~mL}$ of a $37 \%$ solution) was added and the flask inserted into the cavity of a Discovery Microwave System apparatus (from CEM) and heated at $150 \mathrm{~W}$ for 4 min (internal temperature $\left.100^{\circ} \mathrm{C}\right)$.

The mixture was diluted with AcOEt and the solvent washed several times with a saturated solution of $\mathrm{NaHCO}_{3}$. The organic layer was dried over anhydrous $\mathrm{Na}_{2} \mathrm{SO}_{4}$ and the solvent evaporated. The ${ }^{1} \mathrm{H}$ NMR spectrum of the crude showed the presence of pure furan 10 that could be eventually additionally purified by flash chromatography (eluent Hexane: AcOEt 8: $1, \mathrm{Rf}=0.75)$. Obtained $0.49 \mathrm{~g}$, 95\% yield. ${ }^{1} \mathrm{H}$ NMR spectrum enclosed. 

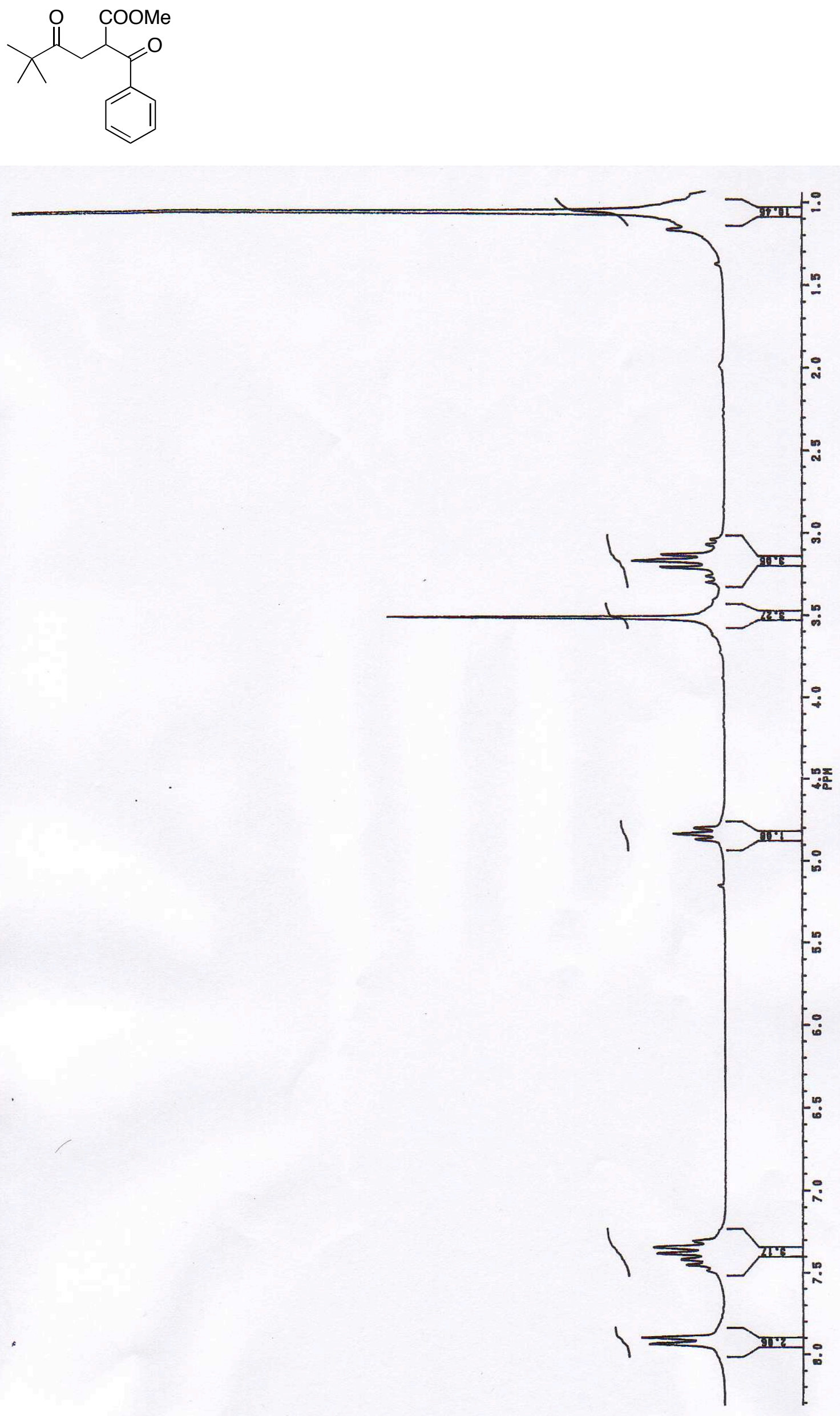


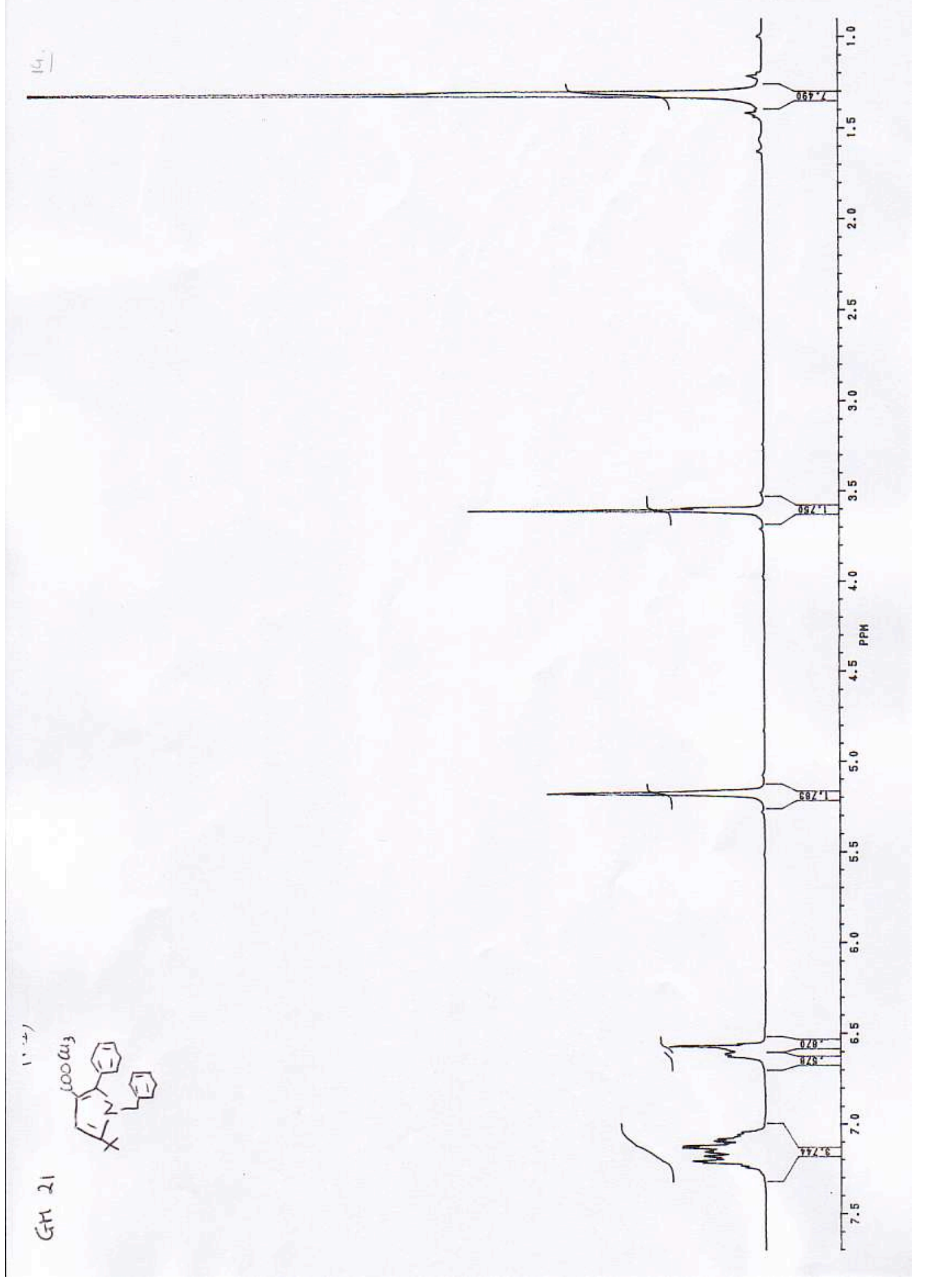




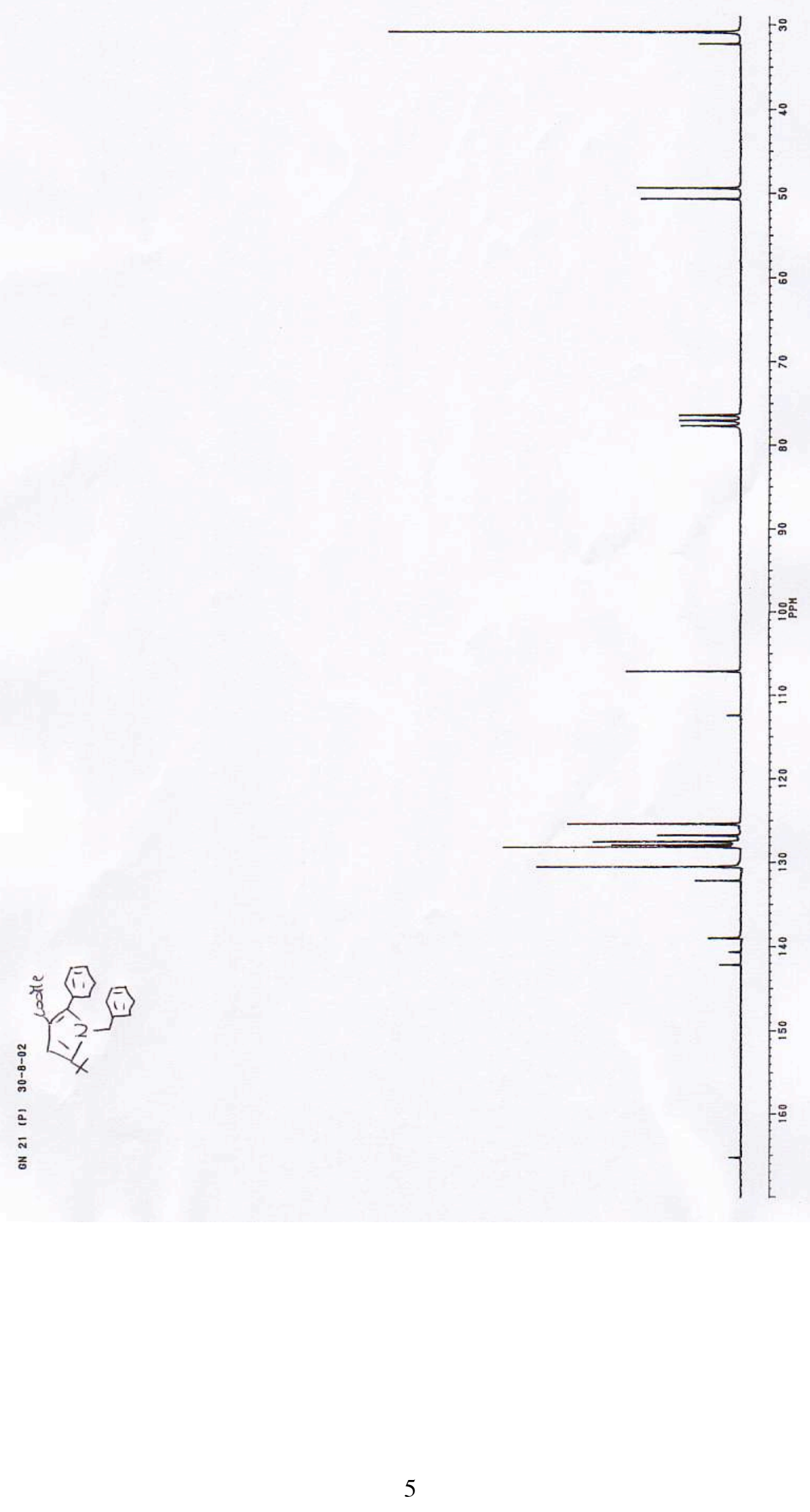




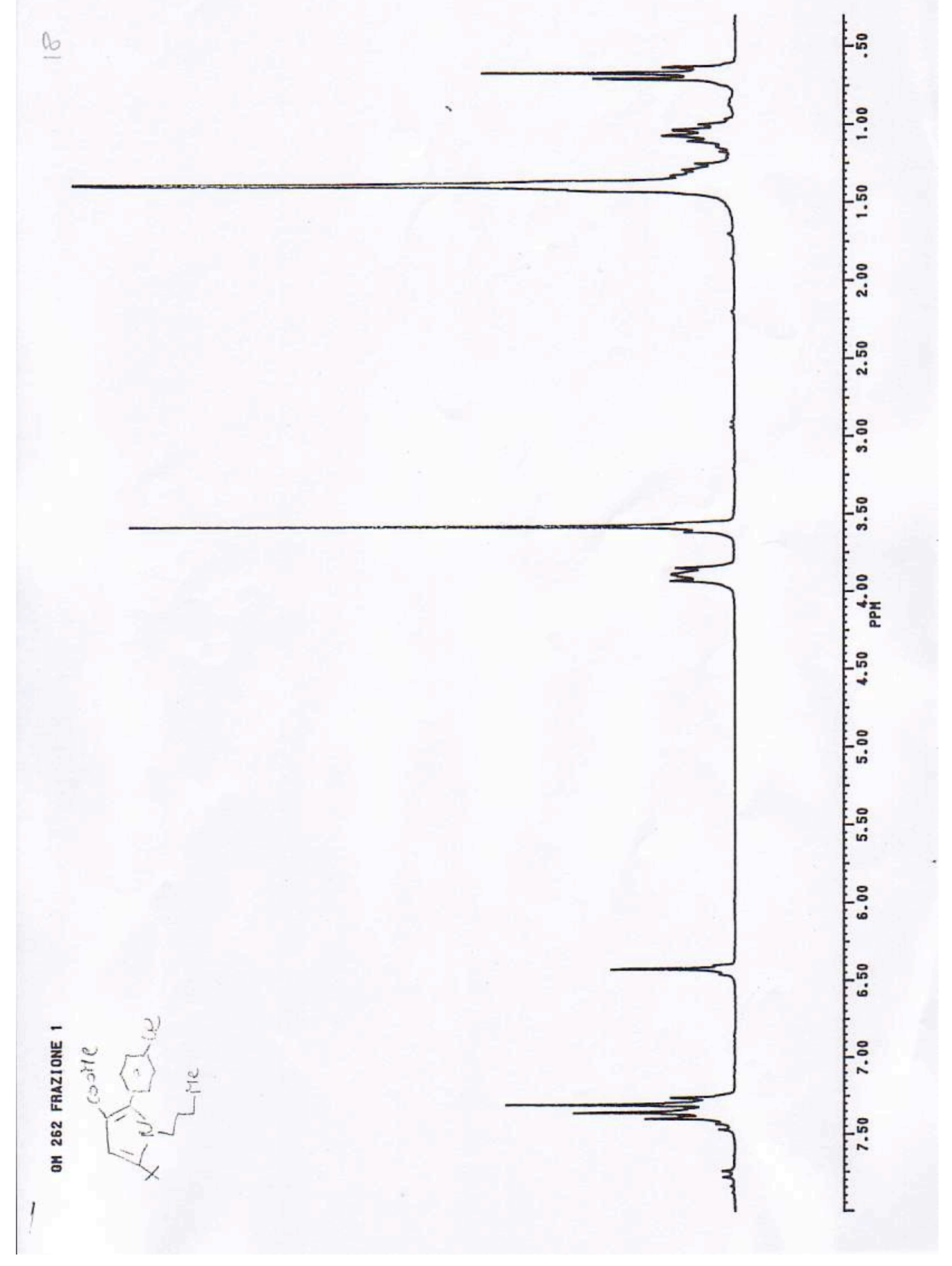




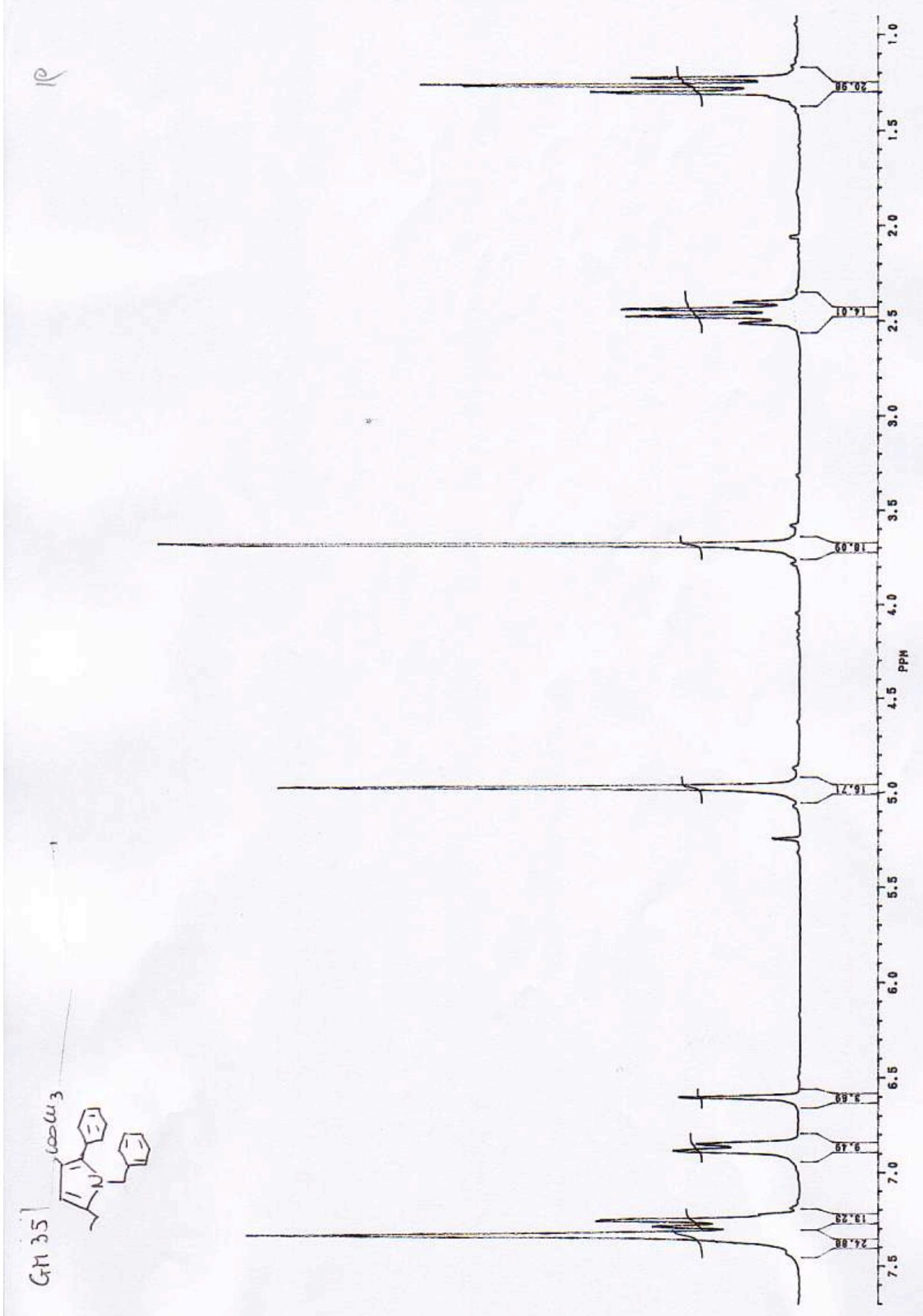




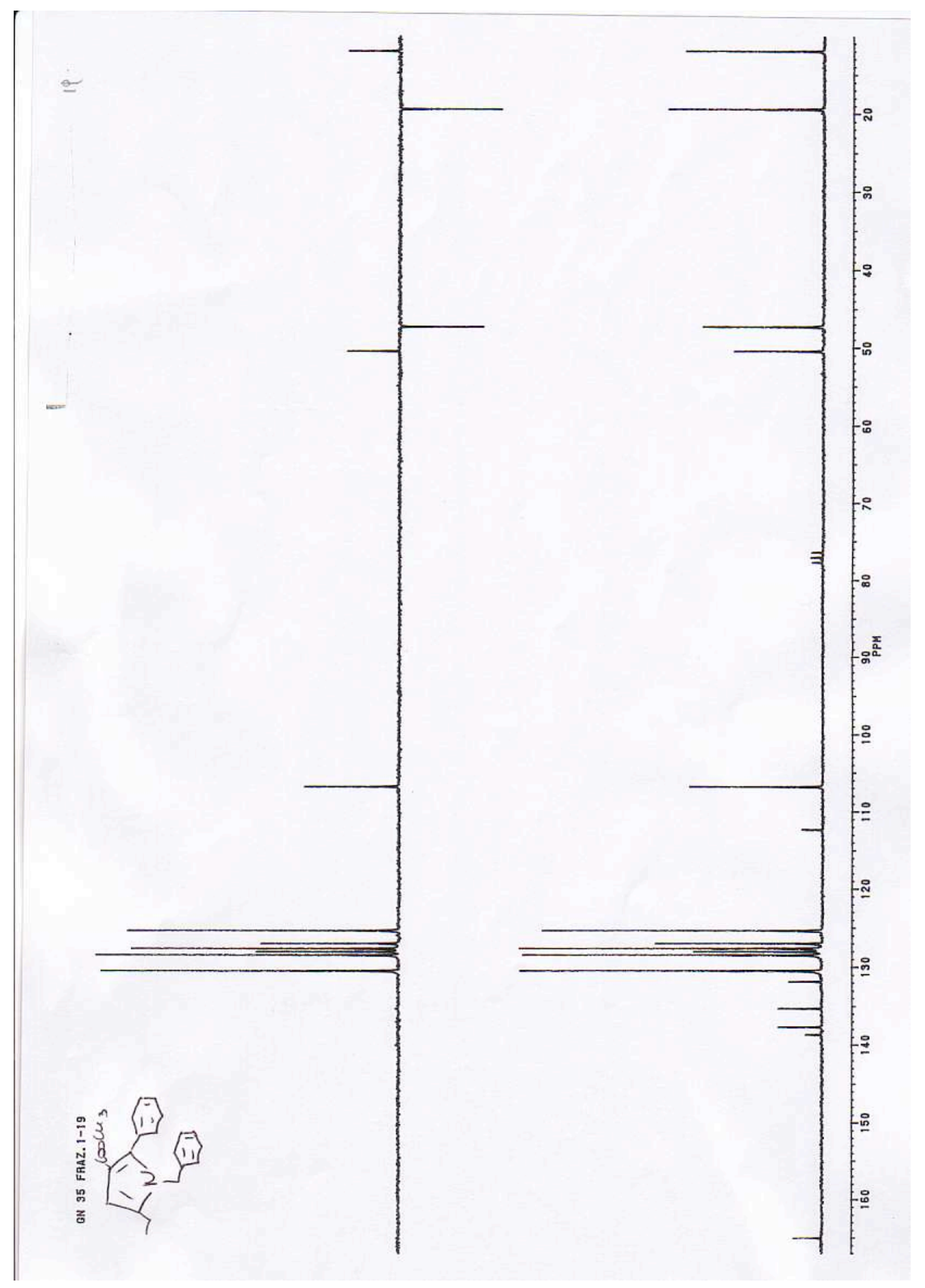




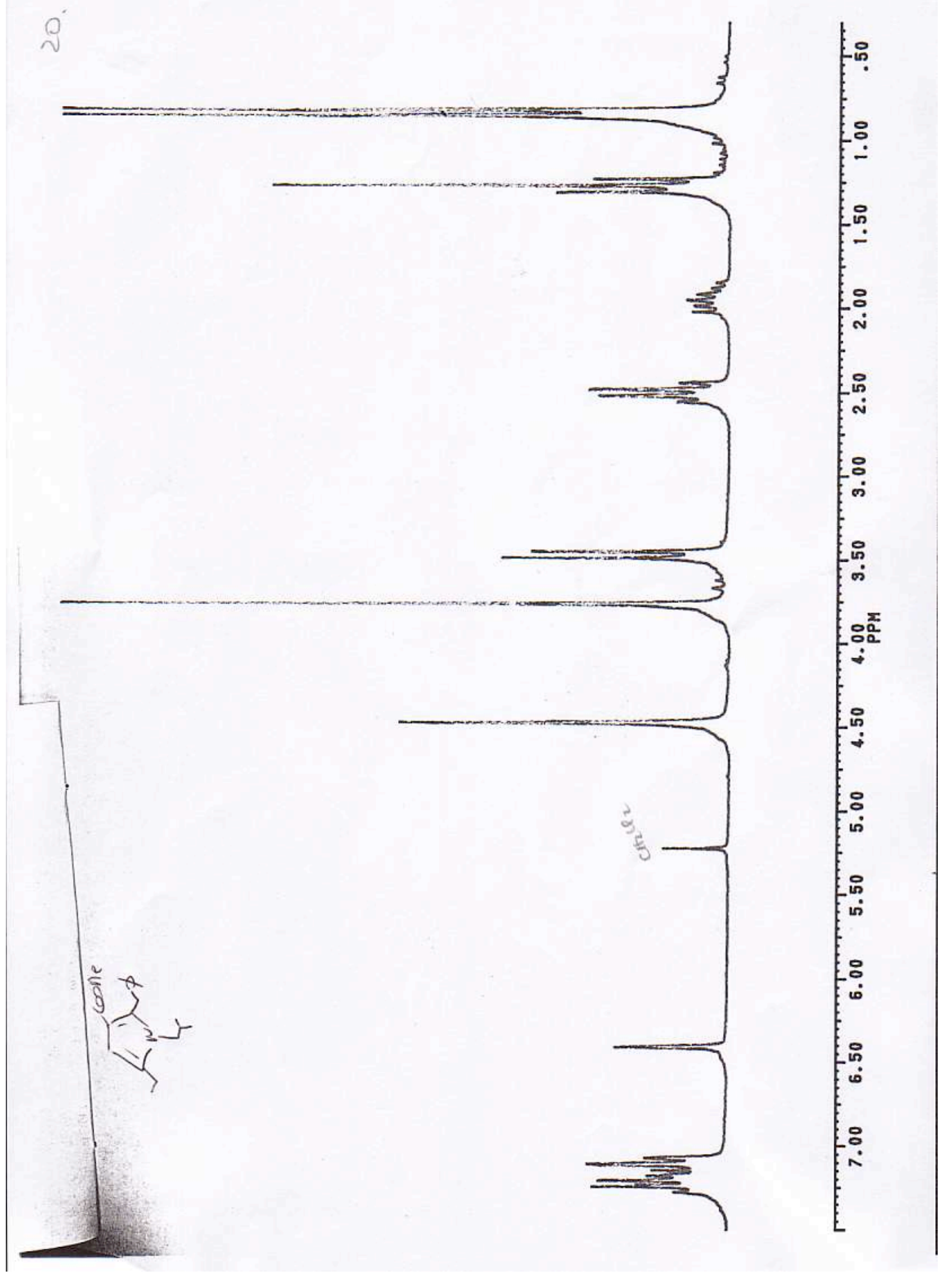




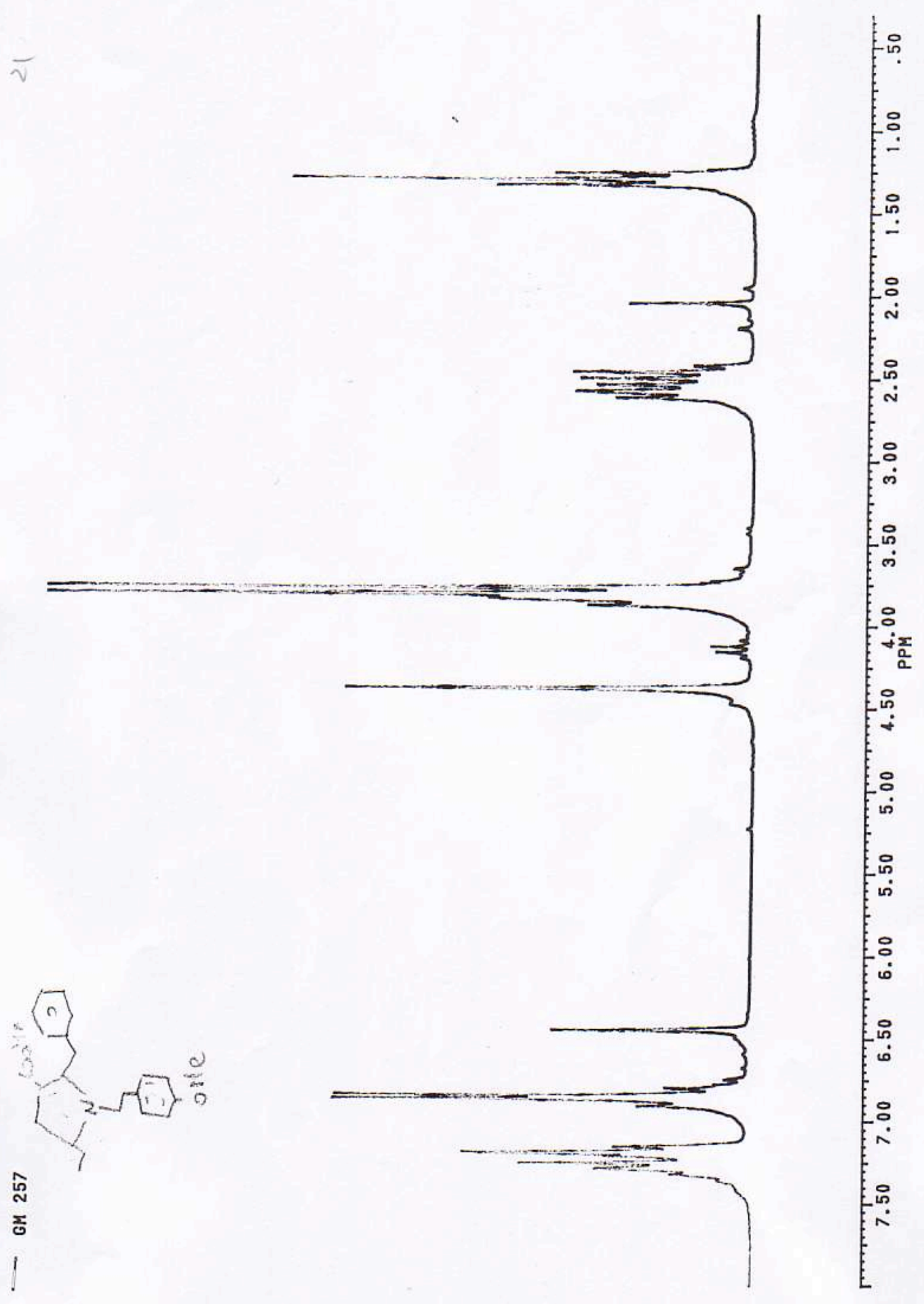



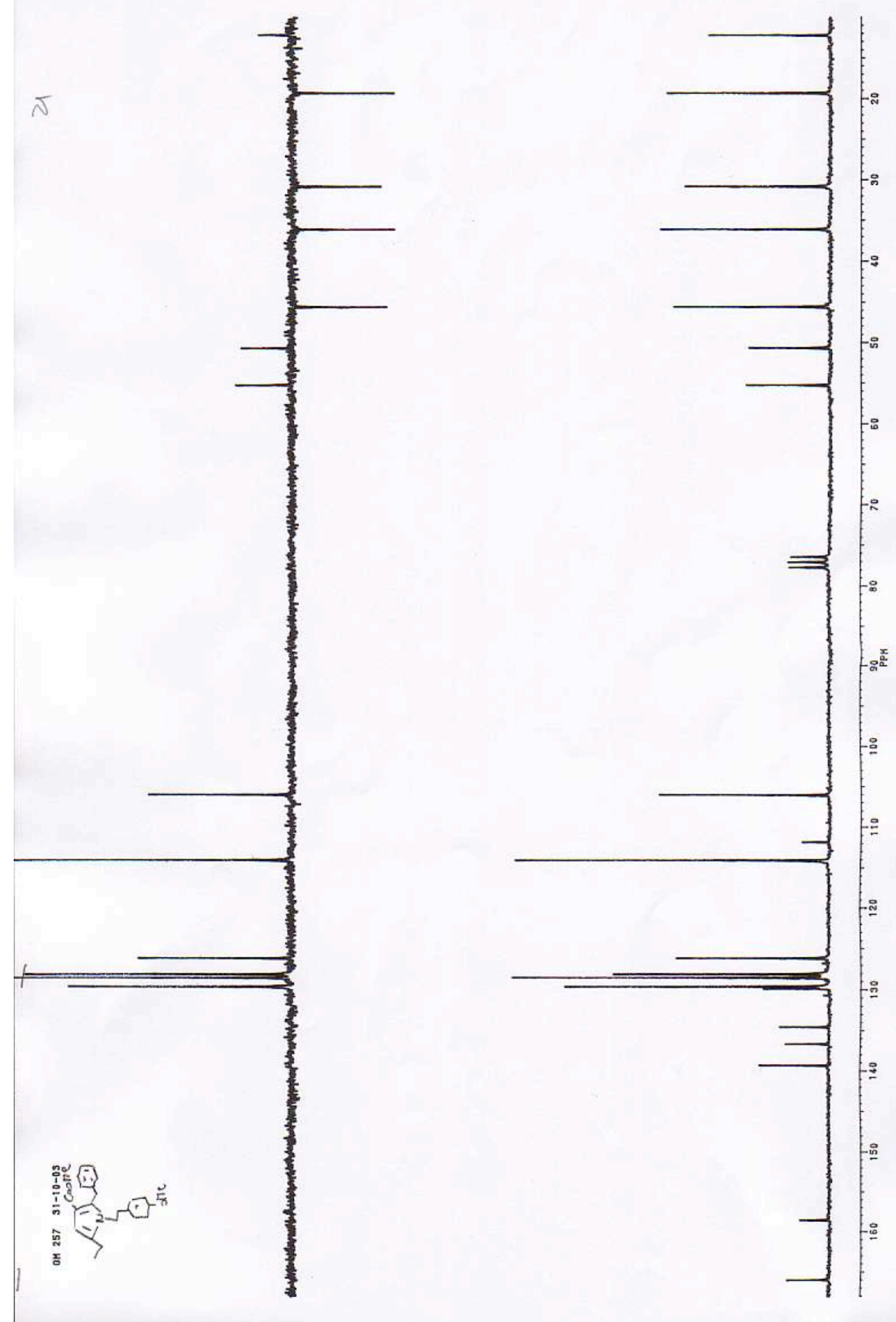

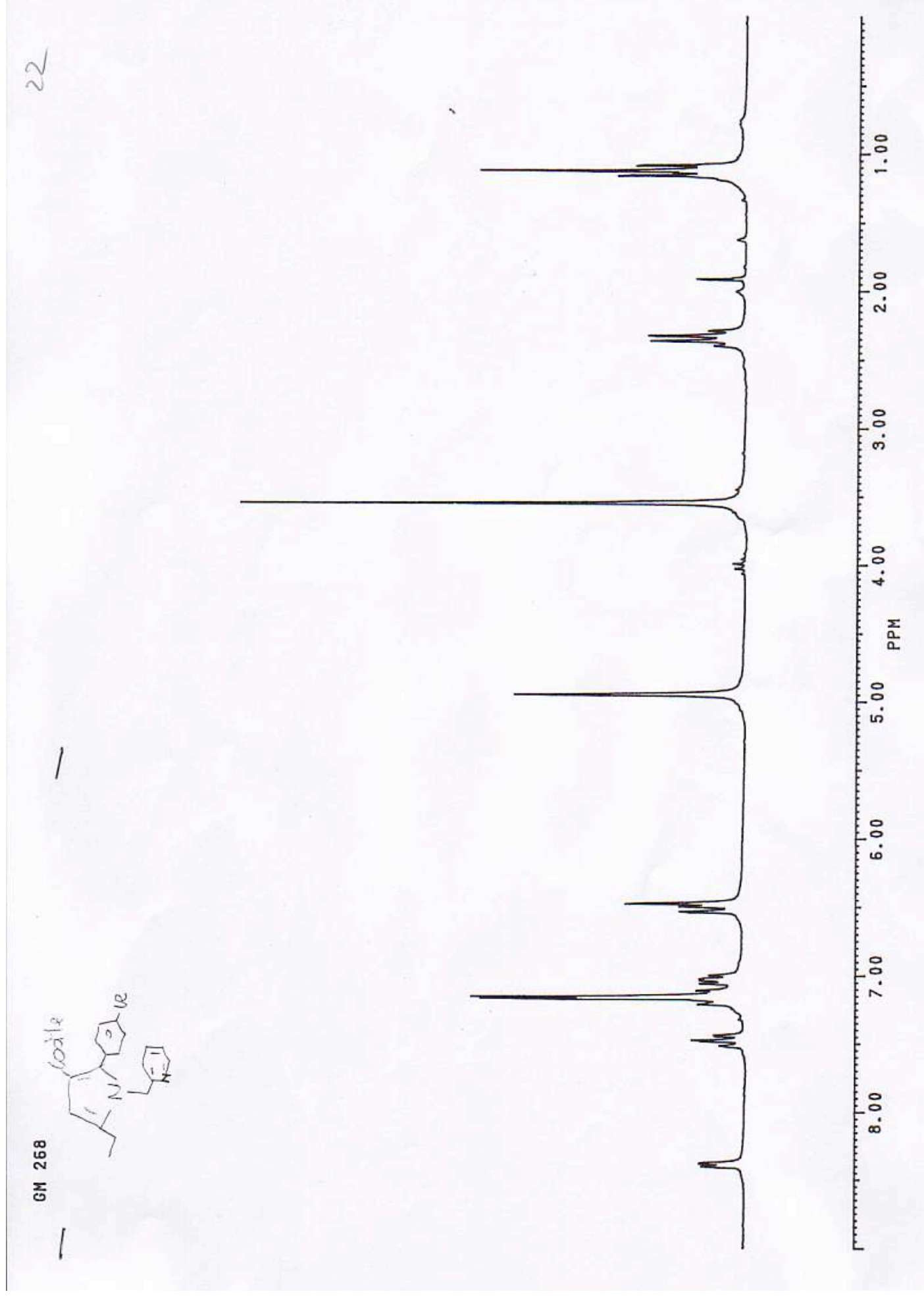


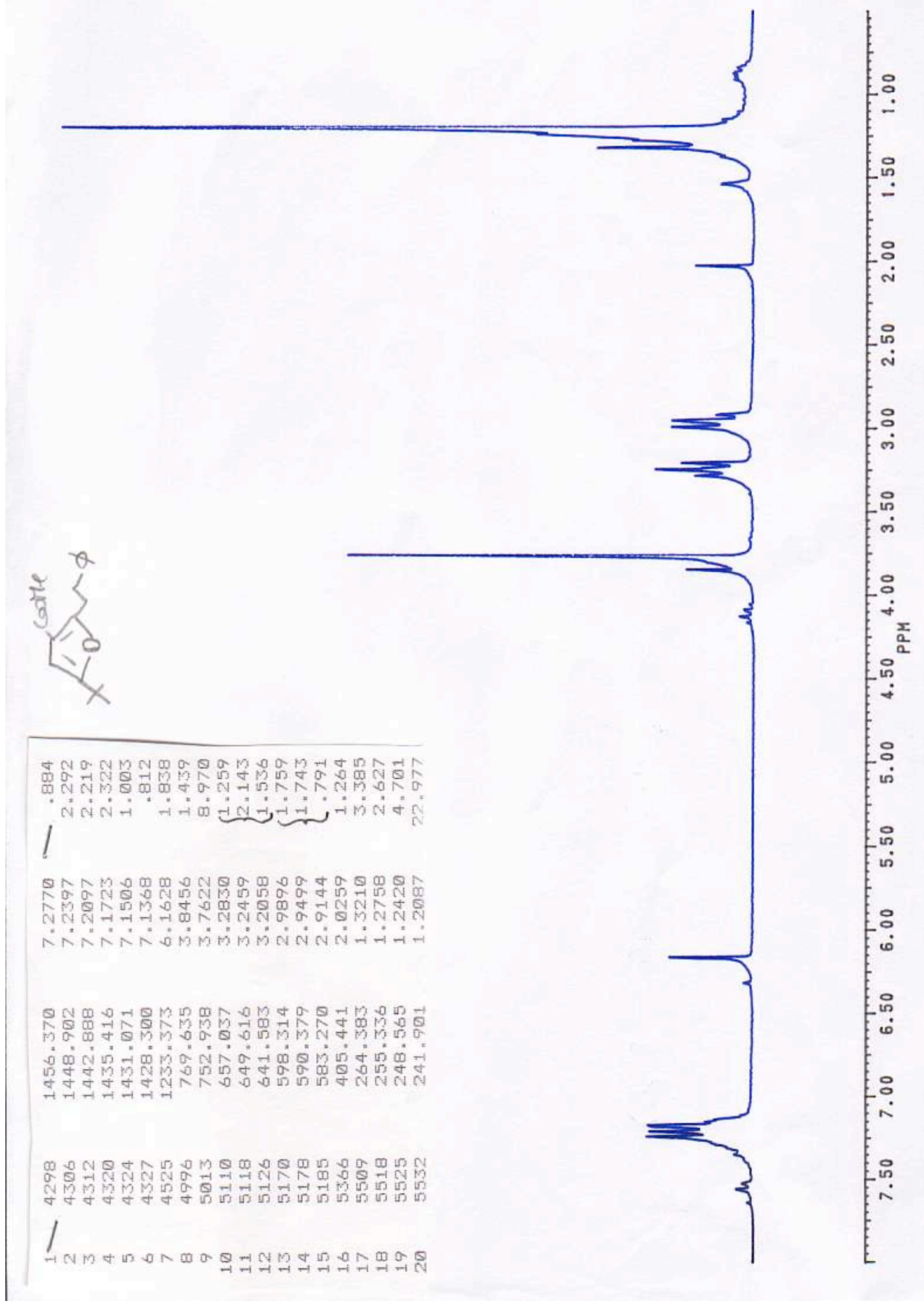

